\title{
Prerequisites for the creation of building materials unified information base as a tool for the construction products' actual cost formation
}

\author{
Elena Zvereva ${ }^{1 *}$, Maria Nemchaninova $^{2}$, and Yulia Tsarionova $^{2}$ \\ ${ }^{1}$ Petersburg State University of Railway Transport of Emperor Alexander I, 190031, St. Petersburg, \\ Russia \\ ${ }^{2}$ Far Eastern State Transport University, 680000, Khabarovsk, Russia
}

\begin{abstract}
The study is devoted to the issues of determining the cost of building materials, affecting the calculation of actual construction cost. These issues are of particular relevance, since there is a reform of the system of pricing and estimated rationing in construction at present, which fundamentally affects the construction actual and reliable cost determination. The proposed federal state information system of pricing in construction, as an electronic resource, a unified base for the cost formation of the building materials involved in the construction products' estimated cost formation.
\end{abstract}

\section{Introduction}

The emergence of problems in the construction products' actual cost formation is currently due to the reform of the current system of pricing and estimated rationing in the construction industry, as well as not only partial filling, but also a systematic change in the base of building materials in the market of building materials and resources, which can be used in determining the actual cost of construction products. These problems are caused by the fact that new materials appear on the building materials market every year, analogues of existing materials, many manufacturers, suppliers offer building materials at prices that differ not only in the industry, but also territorially (different subjects of the Russian Federation and within one subject of the Russian Federation). This circumstance in determining the cost of materials causes unreliability and problems in the formation of the construction products' final cost, since construction products are known to be materialintensive.

The problems of forming the actual cost of materials involved in determining the estimated cost of construction products are considered in the works of Airapetyan N.E., Ardzinov V.D., Baranovskaya N.I., Volkov B.A., Goryachkin P.V., Gumba X M., Kudryavtseva V.A., Kuzmenko A.P., Kukota A.V., Kurochkin A.I., Lavrentyev D.B., Shtokolov A.I., Yakushev V.V. and others. At the same time, these studies do not

\footnotetext{
* Corresponding aiuthor: zverelv@mail.ru
} 
sufficiently disclose the process of forming the actual cost of construction products in the context of reforming the current system of pricing and estimated rationing in the construction industry.

The purpose of the study is determination and substantiation of the building materials' cost in the market of building materials and resources in a changing market environment, ultimately affecting the formation of the actual and reliable cost of construction products.

At the same time, in the period preceding the reform of the pricing system and estimated rationing, it is necessary to highlight the pressing problems that influenced the existing imperfections and contradictions of the current estimated and regulatory framework, namely:

- regulatory and legal (not only the functions and powers delineation lack of the Ministry of Construction in the field of pricing, but also the competences intersection of the Ministry of Construction, the Ministry of Economic Development and sectoral ministries in determining the cost of investment and construction projects; an outdated set of norms, rules, standards and other documents of the methodological base);

- managerial (lack of regulations for interaction between federal and regional authorities; variety of estimate and regulatory frameworks, lack of a unified approach to calculating the planned cost of budget financing objects, etc.);

- technological (high volatility of the construction resources cost at the sectoral and territorial levels, as well as the lack of objective information on the cost of resources and methods for their assessment; the cost monitoring system labor intensity, etc.) [2, 7].

\section{Research methodology}

In connection with the elimination of these shortcomings and contradictions of the current estimate and regulatory framework, in 2015 the Federal Center for Pricing in Construction and the Ministry of Construction of the Russian Federation developed the concept of "500 days reform ", the purpose of which was the formation of a new regulatory, methodological, technological, information base in the context of reforming the pricing system and estimated rationing, taking into account the interests of all participants in investment and construction activities in order to increase the reliability of the actual cost in construction.

An important component in the framework of reforming the pricing system and estimated rationing is to achieve the reliability of the construction cost at the planning and design stages through the following tools of influence:

- clear distribution of executive authorities' functions at all levels, as well as their active information interaction on the platform of the Ministry of Construction;

- wide use of the institute of professional experts for state and independent expertise, including the resources of research, design institutes;

- interaction with sectoral ministries and departments for the development and implementation of innovative technologies, products in the field of construction;

- creation, construction and implementation of technological processes at all stages of an investment and construction project, from research work to industrial production in conjunction with the processes of pricing and estimated rationing;

- the use of individual standards in a limited mode, taking into account the specific features of construction products $[2,4]$.

When analyzing and monitoring the reliability of the estimated cost of construction, for example, the cost of the declared works, services and purchased materials is checked; expediency of additional purchase of materials and additional work (at the insistence of the customer); checking the labor amount and units of equipment used, declared according to the documents; verification of applied coefficients used to determine the current cost of 
construction of objects; control of the number of work performed on those declared according to the estimate, as well as checking the cost, which is indicated for the completion of the construction of the object, etc. In modern conditions, the use of the regulatory and methodological framework in determining the construction products' cost reliability has certain disadvantages, expressed in:

- the use of the latest production technologies calls into question the use of outdated standards for the materials and resources used to date in the formation of the construction products' estimated cost;

- the need to switch from the base-index method to the resource method, reflecting the actual and reliable construction cost determination;

- revision of the Methodological Guidelines and Recommendations for the calculation of price indices in order to determine the reliable cost of construction, etc.

In accordance with the "500 days reform" program, it is planned to switch to the resource method for determining the estimated cost of construction, as well as the use of a single estimate and normative base for the cost of building materials and resources. This database will be open and accessible to all the participants in investment and construction activities in obtaining the necessary data on the cost of basic building materials and resources (costs of operating machines and mechanisms, labor costs).

FSIS CP is a state information system operating on the basis of software, hardware and information technologies, ensuring the collection, processing, storage, placement and use of information necessary to determine the estimated cost of construction. Federal state information system of pricing in construction (FSIS CP) consists of the following subsystems:

- subsystem for monitoring the cost of construction resources (price norms), providing the collection of information on the construction resources' prices, its processing to form the estimated prices of construction resources, placement of the methodology for determining the estimated prices of construction materials and resources, the methodology for applying the estimated norms and estimated prices of construction resources;

- subsystem for maintaining federal registers of estimated standards;

- a subsystem of the construction resources' classifier, which ensures the search and processing of construction resources in the existing information platform in the context of individual classification groups;

- subsystem for checking the estimated cost reliability;

- subsystem of qualification selection of experts and expert organizations, unified register;

- a subsystem for storing information and its changes, providing access to information in the federal state information system of pricing in construction.

- security management subsystem [6].

General Board of state Expert Review, presenting to the Ministry the information base necessary for calculating the cost of building materials and resources, determining the estimated standards, indices used, preliminarily monitors prices on the market for building materials and resources. This function is very important and significant, since it underlies the systematic updating of the classifier of building materials and resources, as well as the development, application and approval of the methodology for determining the estimated prices of building materials and resources required in the future to determine the actual cost of materials and the reliability of the construction products' cost.

In order to fulfill the instructions of the Ministry of Construction of Russia and the implementation of the Action Plan for interaction of the Ministry of Construction of Russia, FAO "Federal Center for Regulation, Standardization and Technical Conformity Assessment in Construction", as well as within the framework of reforming the pricing system and estimated rationing in the construction industry, the General Board of state 
Expert Review of Russia carried out work to update the construction resources classifier (hereinafter referred to as $\mathrm{CRC}$ ) in terms of bringing the current regulatory and technical documentation into compliance and removing brand names (trademarks) from the positions present in the resource parts of the state elementary norms for construction and special construction work. CRC posted in the Federal State Information System for Pricing in Construction. As of today, the classifier contains information about 104985 construction resources $[2,3]$.

The federal executive body dealing with the development, implementation of state policy, as well as the issues of regulation in the field of pricing and estimated rationing, determines the estimated prices of building resources based on monitoring the building materials and resources prices. Estimated prices of construction resources are the documented information on the construction resources cost in a territorial context, established by calculation and for the adopted unit of measurement and placed in FSIS CP, based on the methodology for applying the estimated prices of building resources $[1,7]$.

For the material resources, information on which is provided by the only manufacturer (supplier) of material resources that produces (sells) the corresponding material resources on the territory of the Russian Federation, the estimated price is taken equal to the selling price of such material resources. Procurement and storage costs are determined as a percentage of the estimated price of a material resource in the amount established by the methodology for applying the estimated prices of construction resources. Determination of the estimated cost of material resources is performed for pricing material resources. Pricing includes material resources, the share of which in the total estimated cost of material resources is at least 80 percent, the rest of the resources are classified as others. The assignment of material resources to pricing and others is made on the basis of the consolidated resource sheet and information on the estimated prices of material resources of the base region located in FSIS. The estimated cost of other material resources is determined based on the estimated prices for the base region and the coefficient of transport costs. The coefficient of transport costs is determined by the pricing material resources' total estimated cost ratio, taking into account their quantity, calculated for the construction object and for the base region $[1,8]$.

In accordance with the "Methodology for determining the estimated cost of construction, reconstruction, overhaul, demolition of capital construction, works to preserve cultural heritage (historical and cultural monuments) of the peoples of the Russian Federation on the territory of the Russian Federation" in the absence of FSIS CP data on estimated prices in the current level of prices for material resources, as well as estimated standards for certain types of them, it is allowed to determine their estimated cost according to the most economical option, determined on the basis of collecting information on current prices (market analysis). In the absence of data on individual material resources during FSIS CP their estimated price at the current level is formed on the basis of a calculation in accordance with the estimated standards, information about which is included in Federal Register of Estimated Standards, and the current prices' market analysis results for at least 3 (three) (if any) manufacturers or suppliers in accordance with the provisions of clauses 13 - 21 of the Methodology [8].

One of the main tasks in the field of reforming the pricing system in construction is the transition from the base-index method of forming the cost of construction to the resource method. The base-index and resource-index methods are mainly used in determining the estimated cost of construction of facilities financed from budgetary sources, and the resource method - at the facilities financed from extrabudgetary sources.

The base-index method characterizes the use of a system of current and forecast price indices in relation to the value determined at the base level or at the current level of the previous period. The approach to using price indices to direct cost elements in determining 
the estimated cost is somewhat approximate, because they are general in nature, have errors and do not fully take into account the features of design and space-planning solutions. The resource method is the calculation in current prices and tariffs of the cost elements required to implement a design solution. The resource method for determining the construction cost is a method of making estimates, in which, by type of work, the costs of materials, products and structures, the costs of machines operating time and the costs of workers labor are shown in natural meters, and the prices and tariffs for these resources are taken current (at the time of drawing up estimates). The resource method is a kind of tool that ensures the accuracy and reliability of the construction cost. The advantages of the resource method include the possibility of using various options in the choice of resource indicators, including taking into account the regional and sectoral specifics of construction objects. For example, the Federal State Information System for Pricing in Construction, developed and introduced in order to switch to the resource method for determining the estimated cost of construction, will be open, including a register of estimated standards, manufacturers, information on the main building resources and their cost, etc.

The President of the Union of Estimating Engineers claims that it is wiser to use the resource method to "calculate" the main pricing materials, which give $95 \%$ of the cost, and by the number of items they can make up $10-20 \%$ of the total. The new resource model will provide for price fluctuations, and accounting for basic resources will be kept for a certain time (for building materials - for a quarter; for wages - for a year; for the sale of machines and mechanisms, etc. - for a year).

According to V.V. Yakushev, "we are not ready for the transition to the resource method, because one of its main components is an information system, where we must upload the cost of building materials online for a particular territory. Today this system has a content of no more than $28 \%, 100 \%$ will never be reached, since this data will become outdated. Some manufacturers will leave, some will appear. There should be some intermediate option, a transition period from the basic-index construction method, but with the resource method elements" [3,5].

In the process of reforming the pricing system and estimated rationing, the Union of Estimating Engineers presented a phased plan for the transition to a resource method for determining the estimated cost of construction, which is based on the measures that can further provide a solution to some problems in solving the processes of improving the pricing system and estimated rationing, the public procurement system, settlement systems for completed construction and installation work, namely:

- the transition to the resource method for determining the estimated cost of construction will smooth out the errors of price indices for building materials and resources;

- calculation of transport costs is possible through the development and implementation of new, improved methods of the Ministry of Construction of the Russian Federation, which will affect the actual cost of materials and, accordingly, the construction actual cost reliability;

- the possibility of justifying the cost of the main building materials with line-by-line checking them in the estimates and acceptance certificates for the completed construction and installation works, as well as their replacement in accordance with the change in project documentation and consideration in the classifier of building materials and resources in the context of other classification groups, etc.

It is necessary to highlight some of the positive results of the reform of pricing and estimated rationing, because to date, created and developed:

- single coordination center - Ministry of Construction (FAO "Federal Center for Regulation, Standardization and Technical Conformity Assessment in Construction"); 
- current estimate and regulatory framework (Federal Unit Pricing, Territorial unit rates, Industry unit rates), unified state budget and regulatory framework (USBR) by territorial and sectoral components;

- implementation in all areas of construction activities of a single classifier and resource codifier;

- collegial scientific and expert body (agreement on information interaction with authorized regional executive bodies of state power) with the establishment of responsibility, with large self-regulatory organizations (SRO), associations of building materials and equipment manufacturers;

- federal state information system of pricing in construction (FSIS CP), constant tracking of the construction resources cost, free access to the database;

- in the field of pricing, a full set of regulatory documents has been developed that are used to calculate the cost of objects financed by all levels of the budget, due to measures of state support and extra-budgetary funds, as well as objects transferred to state ownership upon completion of construction, or in the process of operation on the basis of price norms and etc. $[2,3,5,7]$.

\section{Conclusion}

Thus, in this work, based on the results analysis of the reform in 2015 - 2020 the system of pricing and estimated rationing in the field of construction, carried out by the Accounts Chamber of the Russian Federation, it was determined that the transition to a new pricing model in the context of reforming the industry was not achieved. The Ministry of Construction in Russia continues to reform the system of pricing and estimated rationing, through the transition to a resource method for determining the estimated cost of construction using FSIS CP. The current estimate and regulatory framework have many problems, imperfections and contradictions, and needs significant adjustment, because the reflection of the actual cost in construction is the basis for effective relationships between the participants in investment and construction activities. In this regard, it is necessary to improve the methods for calculating the actual cost of materials, filling out the federal state information system for pricing (FSIS CP), optimization of the procurement system for building materials, etc.

\section{References}

1. P.V. Goryachkin, A.I. Shtokolov, A.P. Kuzmenko, N.E. Airapetyan, Methodical guide on the budget case, 2019. Lan': Electronic Library System. URL: https://e.lanbook.com/book/145079. Access mode: for authorized users.

2. D.B. Lavrentyev, Young Scientist 11, 229-231 (2017).

3. Monthly bulletin of the Regional Center for Pricing in Construction, LLC Tertsya 9, 85 (2018).

4. Monthly bulletin of the Regional Center for Pricing in Construction, LLC Tertsya 11, 80-82 (2018).

5. Monthly bulletin of the Regional Center for Pricing in Construction, LLC Tertsya 12, 96 (2018).

6. Resolution of the Government of the Russian Federation of September 23, 2016 No. 959 "On the Federal State Information System for Pricing in Construction".

7. Monthly bulletin of the Regional Center for Pricing in Construction, LLC Tertsya 1, 68-69 (2019). 
8. Methodology for determining the estimated cost of construction, reconstruction, overhaul, demolition of capital construction projects, works to preserve cultural heritage (historical and cultural monuments) of the peoples of the Russian Federation on the territory of the Russian Federation, Instead MDS 81-35.2004, Moscow, Gosstroy, Russia, 2020. 